\title{
Integrated Mineralogical Characterisation of Banded Iron Ores of Orissa and Its Implications on Beneficiation
}

\author{
J. K. Mohanty ${ }^{1 *}$, M. S. Jena ${ }^{1}$, A. K. Paul ${ }^{2}$ \\ ${ }^{1}$ Council for Scientific and Industrial Research (CSIR), Institute of Minerals and Materials Technology, Bhubaneswar, India \\ ${ }^{2}$ Department of Geology, Utkal University, Bhubaneswar, India \\ Email: jkmohanty@immt.res.in
}

Received July 24, 2012; revised August 29, 2012; accepted September 12, 2012

\begin{abstract}
Iron is a primary raw material for steel industry. Increase in demand for steel puts pressure on iron resources of India in respect of its grade and reserve. With increase in demand for good grade of ore vis-a-vis its limited reserve, the utilization of low to medium grade iron ores is the order of the day with adoption of advanced beneficiation techniques. In order to find out the effective way of utilization, an in depth mineralogical study is essential as it throws light on the mineralogical peculiarities associated with the ores which affect the resultant beneficiation technique as well as the final product. In order to have a detail insight into the different mineralogical attributes, various characterisation studies megascopic, microscopic (both optical \& electron), XRD, mossbauer and VSM are undertaken on the iron ores from different iron ore formations of Orissa. Importance of integrated mineralogical characterisation in beneficiation of iron ores is discussed.
\end{abstract}

Keywords: Iron Formation; Characterization; Beneficiation; Mossbauer Spectroscopy; Orissa

\section{Introduction}

Iron is the second most abundant metallic element in the Earth's crust and accounts for $5.6 \%$ of the lithosphere. Iron like most metals, is found in the Earth's crust only in the form of an ore i.e. combined with other elements such as oxygen or sulfur. Hematite and magnetite are the two important iron ores from which iron is extracted. Of these, hematite is considered to be superior owing to its high reserve. Hematite is the main iron ore which is extensively used for manufacture of iron and steel in India. The grade/quality of ore determines on different iron making processes. With the iron and steel industries are becoming increasingly conscious about the need for improving productivity, the approach is towards obtaining cleaner ore with higher Fe content having least gangue and of homogeneous and consistent quality.

The world reserve base of crude iron is estimated to be 370 billion tones [1]. It has been estimated that the world resources are in excess of 800 billion tonnes of crude ore containing more than 230 billion tonnes of iron. Iron ore deposits are distributed in different regions of world under varied geological conditions and in different geological formations. The largest concentration of ore is found in banded sedimentary iron formations of Precambrian age. These formations constitute the bulk of world

"Corresponding author. iron ore resources. The top countries in the world in order of their iron resources are given in the Figure 1. Among the iron ore producing countries, India ranks fourth in terms of quantity produced following China, Brazil and Australia.

India has large reserves of good quality iron ore. India is endowed with huge resource base of 25.24 billion tonnes of iron ore of which 7.06 billion tones are reserve and 18.18 billion tones are remaining resources [1]. These iron ores occur in different geological rock groups/

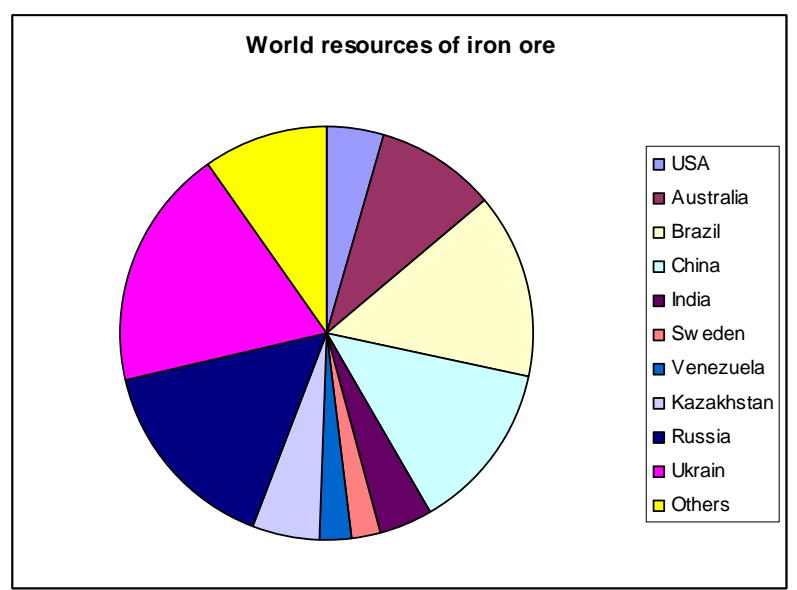

Figure 1. Distribution of iron ore resources in different countries of world. 
formations in different time domains. On the basis of mode of occurrence and origin, the iron ore deposits are divided into five groups viz. Banded Iron Ore Formation (BIF), sedimentary iron ore deposits of sideritic and limonitic composition, lateritic ore derived from subaerial alteration of gneiss, schist etc., Ti-V-magnetite deposits and fault and fissure filling deposits. Among these, the largest concentration of economic deposits is found associated with volcano-sedimentary Banded Iron Formation (BIF) of Precambrian age. The BIF, mainly comprising of Banded Hematite Quartzite/Banded Hematite Jasper (BHQ/BHJ) contains iron in the range of $25 \%$ to $40 \%$. By supergene enrichment, the total iron content of the BHQ/BHJ has in many places gone upto about 55\% $65 \%$ making them very good quality ore. Most of the Indian deposits are similar to those of Lake Superior Type. Extensive outcrops of BIF are found in the states of Orissa, Jharkhand, Chhatisgarh, Karnataka, etc. The most common names used in India to designate BIF are BHQ and BMQ. Hematite accounts for more than $98 \%$ of the total reserve. Major hematite resources are located mainly in Orissa (33\%), Jharkhand (28\%), Chhatisgarh (19\%) and Karnataka (11\%).

Banded Iron Formations are chemically precipitated enigmatic rocks constituting alternate iron-rich and iron - poor (amorphous silica rich) layers. This dichotomous compositional dowering is usually expressed on several scales at any given outcrop, from fine sub-millimeter-scale varve like laminae to meterscale bands. Even on a microscope scale, the boundary between the ferruginous and siliceous layers is distinctly observed.

Orissa holds a lion share of the total Indian reserve. The iron ore resources are distributed in three iron ore formations viz. BIF 1, BIF2 and BIF 3 (Figure 2). The iron ores deposits are distributed mostly in Keonjhar, Sundergarh, Jajapur and Mayurbhanj districts. A small deposit is present in Koraput district which has been very scantily studied. Due to various socio-economical constraints and poor locational dynamics, it is at present not being explored/exploited.

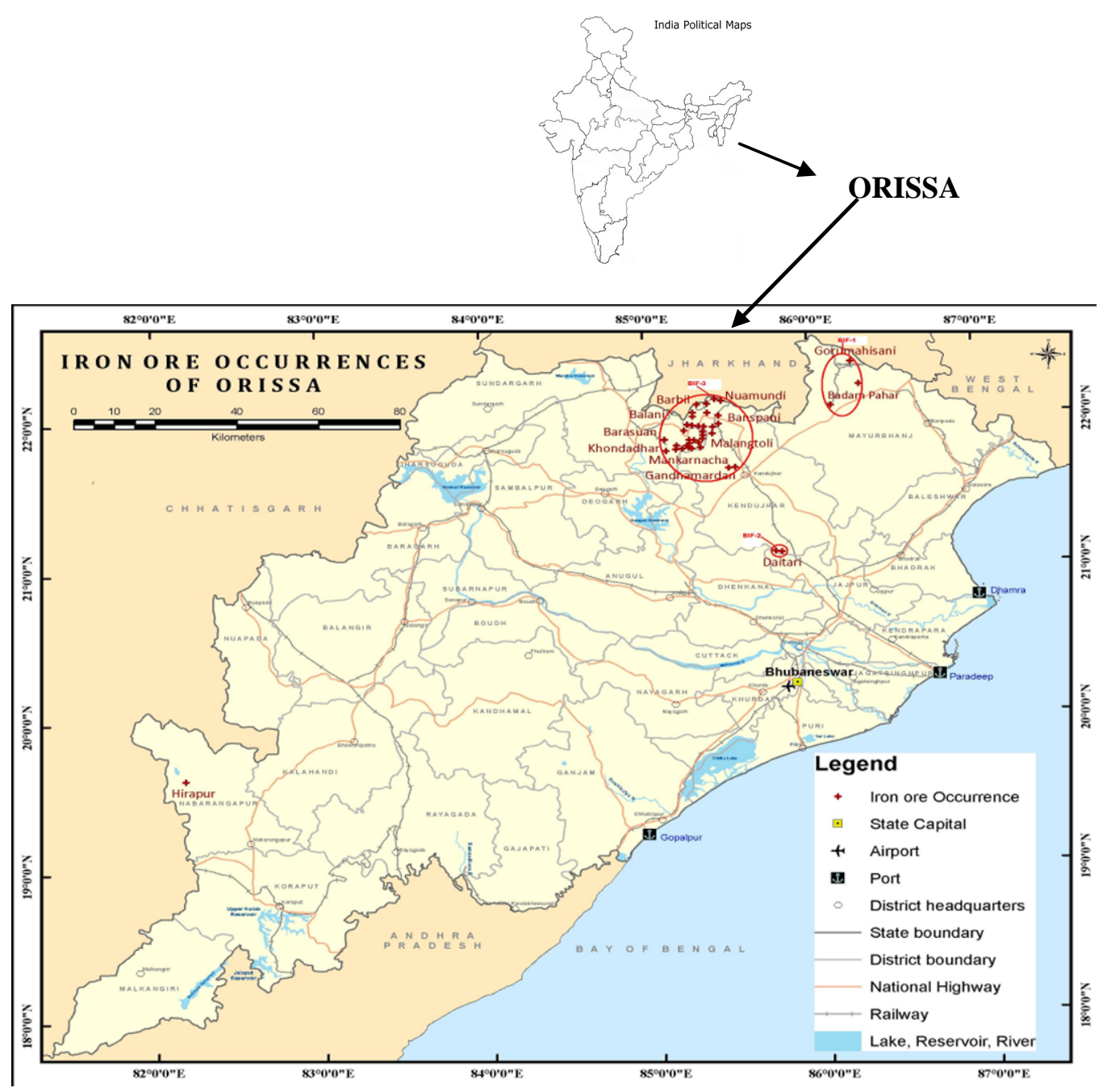

Figure 2. Iron ore occurrences in Orissa. 
Due to pressure of bullish Iron and steel industry for a continuous supply of good grade raw material, full scale mining activity is going on in the northeastern Orissa where most of the iron ore mines are situated. Keeping abreast with the demand, Govt. has planned for annual production of 110 MT steel by 2020 which will be requiring 170 million tonnes of iron ore. A target set in the policy suggests a production of 300 million tonnes of iron ore by 2019-2020 to meet export and domestic demand. Looking into the demand for good grade which is much less compared to medium and low grade ores, enough stress is being laid on the utilization of these leaner ores to augment the resource position to support the ensuing steel production. As these ores can not be used straight way, they need upgradation of Fe content which can be achieved by various beneficiation techniques. The basis for any effective beneficiation process lies in a detail mineralogical and chemical characterisation of the raw material. The paper gives an account of detail mineralogical characterisation of iron ores from the three iron ore formations and its significance in optimum beneficiation of the low/medium grade ores.

\section{Materials \& Methodology}

A few iron ore samples are collected from different locations of the three iron ore formations for their detail mineralogical and chemical characterisation which finally will give an insight to their beneficiation characteristics. Mineralogical characterisation is very important in study of these types of ore which will provide information about the mineralogy and different textural attributes to decide upon the right choice of beneficiation practices. The selection of suitable beneficiation processes depends on the physical characters of iron minerals and quartz. An integrated approach towards mineralogycal characterisation was adopted using various techniques such as optical microscopy, XRD, Electron microscopy, Mossbauer spectroscopy and VSM. The results of mineralogical characterisation have some direct application in iron ore processing.

XRD was carried out with Philips PW3710 X ray unit having Mo target ( $\alpha_{1} 0.7093$ and $\left.\alpha_{2} 0.71359\right)$ and operated at $45 \mathrm{kV}$ and $35 \mathrm{~mA}$. The operating parameters are Divergence slit (1/4) and receiving slit of 0.2 , step size $(2 \theta)$ of 0.020 and 1s/step with continuous scan from $2 \theta 6$ to 40 .

Electron microscopic study was carried out by JEOL JSM 6501 operated at $15 \mathrm{kV}$ with 11 to $14 \mathrm{~mm}$ working distance after the sample is coated with carbon.

Mossbauer spectra have been recorded by a conventional constant acceleration spectrometer at $300 \mathrm{~K}$ using $25 \mathrm{mCi}{ }^{57} \mathrm{Co}$ source embedded in Rh matrix. About 60 $70 \mathrm{mg}$ of powders from samples was sandwiched inside a copper ring of $12 \mathrm{~mm}$ inner diameter with cello-tape on both sides. The experimental data were fitted with a least square fitted computer program considering Lorentzian line shapes of the spectrum and parameters were calculated by taking the spectra of bcc iron as a calibration.

Magnetization study was carried out to find out the natural magnetic behaviour of the samples containing different iron phases. For this purpose, room temperature magnetization as a function of applied field has been measured for all samples for both positive and negative field range to get the hysteresis curves (Figure 7). A vibrating sample magnetometer (VSM, ADE Technology, USA) has been used for magnetization measurement upto a highest field of $1.75 \mathrm{~T}$.

\section{Results}

The three iron formations differ in their mineralogy (both ore and silicate bands) and geological features. The distinction between them is based on iron mineralogy and silicate phases, degree of metamorphism and effect of weathering/alteration. BIF I is represented by magnetite and chert with little martite, hematite and goethite. Occasional presence of pyrite is observed. It has undergone metamorphism in moderate to high temperature and pressure conditions. BIF II is mostly martitised magnetite and quartz. Martite is a variety of hematite pseudomorph after magnetite. It has witnessed metamorphism under low to moderate temperature and pressure. BIF III that mostly consists of hematite and jasper (a red variety of quartz) shows almost no sign of metamorphism. Results of detail mineralogical study are given below.

\subsection{Megascopic Study}

Banded iron formation is a system where both iron and silica are involved to give rise to a banded appearance. It implies that iron rich and iron poor-silica rich layers appear alternatively giving rise to a banded nature to the proto-ore. Figure 3(a) depicts a megascoipc view of a banded iron ore where both iron rich grey and silica rich red bands are alternatively present giving a banded appearance to the ore. Figure 3(b) is a megascopic view of a banded hematite quartzite where iron ore bands are fractured and fragments of iron ore are embedded in quartz matrix. The ore generally breaks along the banding which is generally the iron and silica boundary. The scale of banding is very important for physical beneficiation perspective as well as downstream operations. The banding varies from mega to micro depending on the thickness of the corresponding layers. Mega or coarse banding has an advantage that the constituent parts can be easily separated where as separation is difficult if the bands are very thin. Similarly if the iron ore is fragmented to a very fine size and intermixed with quartz, then separation of iron from quartz will be very difficult. 


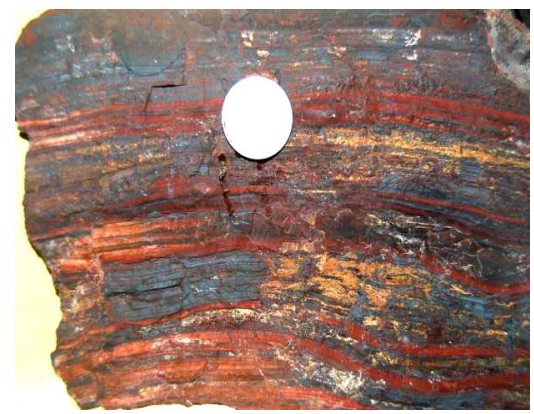

(a)

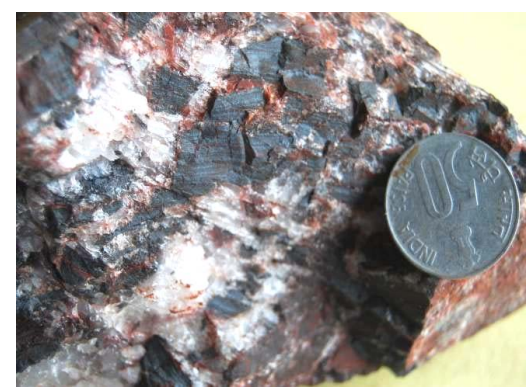

(b)

Figure 3 (a) Banded iron ore showing coarse bands of iron (steel grey) and silica (red), (b) Deformed banded ore showing fragments of iron ore (steel grey) are set in a matrix of quartz (white).

\subsection{Microscopic Study}

Representative polished sections are prepared and microscopic study was undertaken to find out the mineralogy, texture/micro-structure and modal distribution of the minerals in the ore.

\subsubsection{Optical Microscopic Study}

Microscopic study reveals that the ores are mainly composed of iron oxide-hydroxide phases in different proportions with varying amounts of silicate minerals like quartz and clay. Hematite, magnetite and goethite are the major iron minerals. Goethite, the major mineral in iron ore samples from Hirapur area shows well developed colloform banding, a characteristic texture indicating colloidal precipitation (Figure 4(a)). The banded iron formation is due to presence of alternate iron rich and iron poor-silica rich bands (Figure $\mathbf{4 ( b )}$ ) and this feature is very characteristic of precipitation of a solution alternating with iron rich and silica rich materials [2]. The banded iron ores from different deposits exhibit macro banding to microbanding (Figure 4(c)). The scale of banding is very important from beneficiation point of view as during communition process, the coarse bands will separate out considerably where as the microbands get camouflaged between iron rich and iron poor fractions

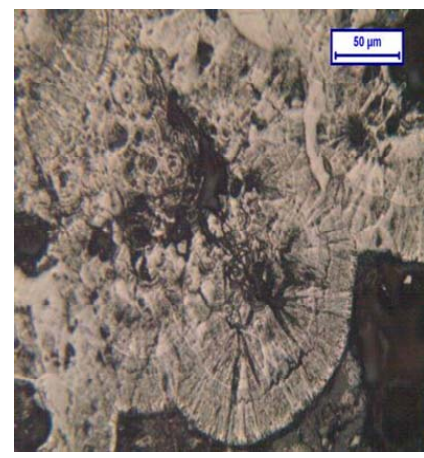

(a)

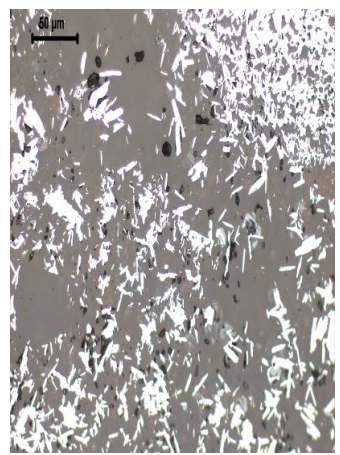

(d)

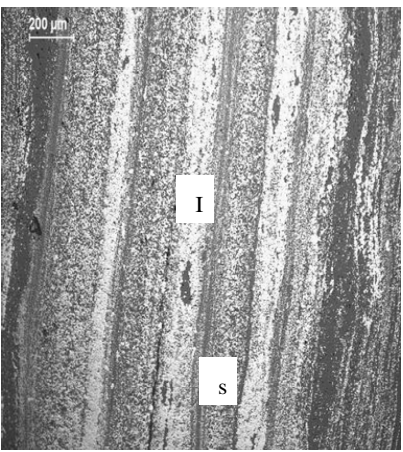

(b)

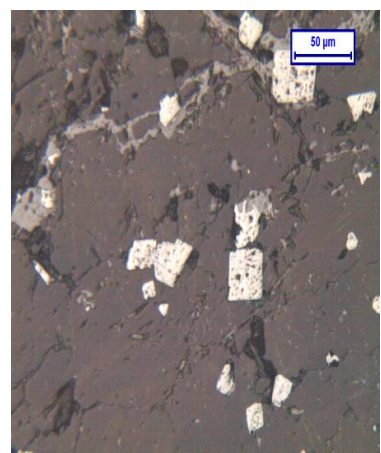

(e)

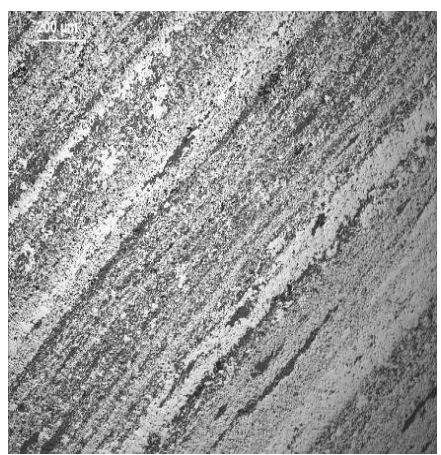

(c)

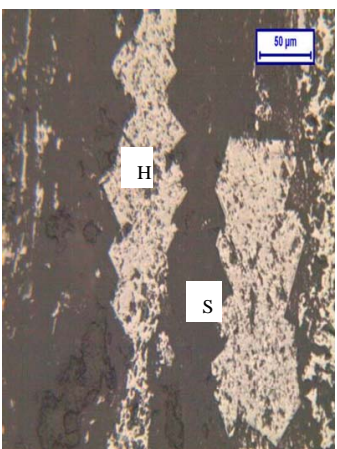

(f)

Figure 4. (a) Colloform banding of goethite in iron ore, (b) Alternate bands of iron rich and silica rich in banded hematite jasper, (c) Alternate bands of hard laminated ore showing contrasting mineralogical association and texture, (d) Specular hematite grains in a silica matrix in a laminated ore, (e) Distribution of euhedral hematite in a silicate matrix in BHJ, (f) Hematite grains join together to give a chain appearance in quartz matrix, I-Iron Rich, S-Silica Rich, H-Hematite. 
leading to difficulty in selection of unit operations for processing. Figure 4(d) depicts skeletal hematite in silicate matrix. Figure 4(e) shows presence of euhedral hematite grains in a silica matrix. When bigger crystals join together head on, they look like a ropy chain (Figure 4(f)). Iron ores representing BIF 1 consist mostly of magnetite and quartz. Besides a few pyrite grains are found to be present. Hence this type of ore is difficult to beneficiate.

\subsubsection{Electron Microscopic Study}

Scanning electron microscopic study was carried out to find out the textural relation between major mineral phases of BIF in a fine scale. Presence of very fine hematite grains with in quartz (Figure 5(a)) and irregular shaped quartz in hematite (Figure 5(b)) is observed. The hematite grains in silicate matrix are extremely fine grained. So it is very difficult to liberate the hematite grains for its upgradation. Figure 5(c) shows an enlarged hematite crystal having inclusions of quartz where as presence of irregular shaped hematite is found to be present within quartz grains and also between quartz grains (Figure 5(d)). These findings have a great influence on beneficiation of this type of iron ores. The study indicates that total separation of iron minerals from such silicate association is very difficult and may not be economic as this may involve lot of grinding to finer size for complete liberation as selection of unit operations for physical beneficiation is based on liberation of the mineral grains.

\subsection{XRD Study}

$\mathrm{XRD}$ of iron ore samples from iron formations was carried out and the major minerals are identified. XRD study

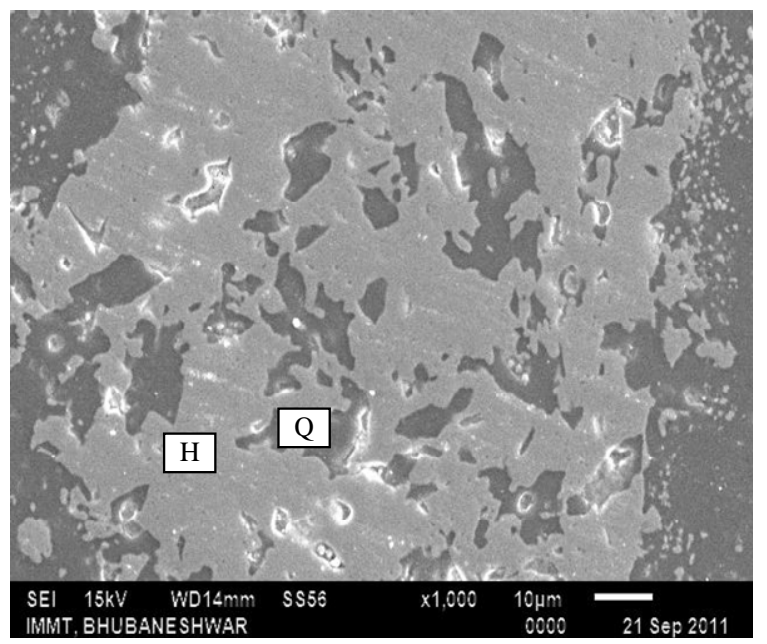

(b)

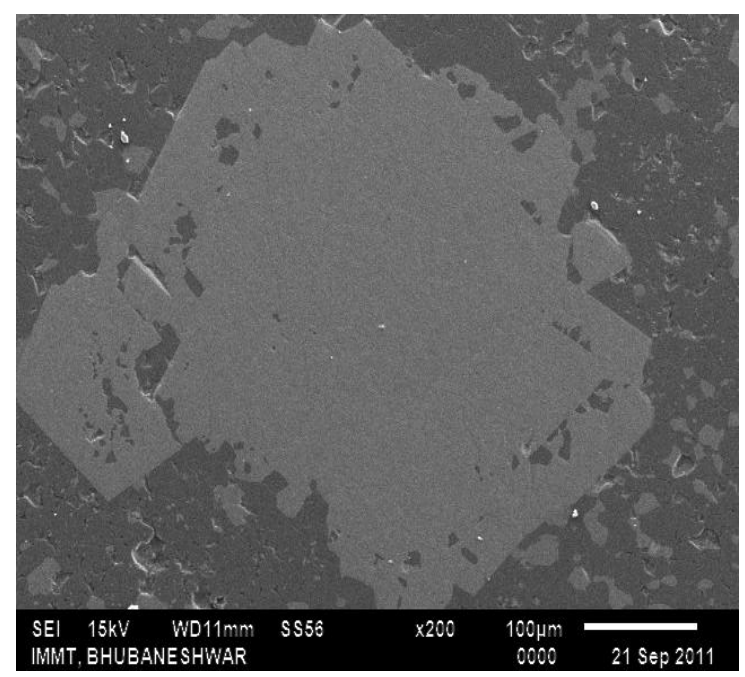

(c)

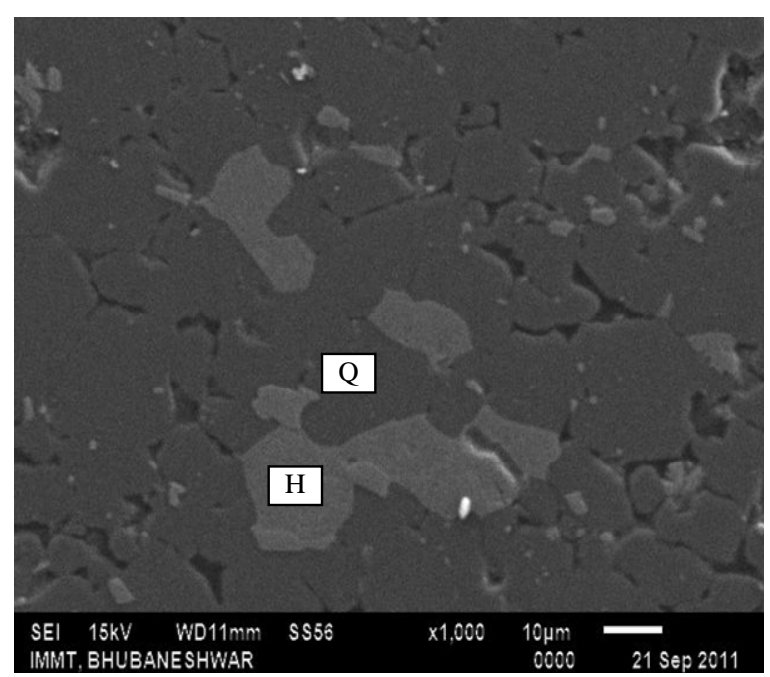

(d)

Figure 5. (a) SEM of BHJ sample showing random distribution of fine hematite grains in quartz matrix, (b) SEM showing distribution of irregular quartz grains in hematite, (c) SEM showing distribution of very coarse as well as fine hematite grains, (d) Irregular distribution of coarse and fine hematite grains in a quartz matrix in BHJ. H-Hematite, Q-Quartz. 
indicates that samples from Hirapur (HP) are predominated by goethite with minor amounts of hematite. Samples representing BIF 1 have magnetite as the major mineral phase with minor amounts of hematite and quartz. Hematite, goethite and quartz are the principal minerals of BIF 2. Depending on the degree of alteration, the proportion of hematite and goethite varies in the samples. The samples representing BIF 3 mostly consist of hematite and quartz. The quartz is actually jasper; a variety of quartz which imparts a brilliant red colour to the banded ore after good polish. From the XRD study, it is observed that hematite and quartz are the major minerals in BIF 2 \& 3 where as magnetite is principal mineral in BIF 1 .
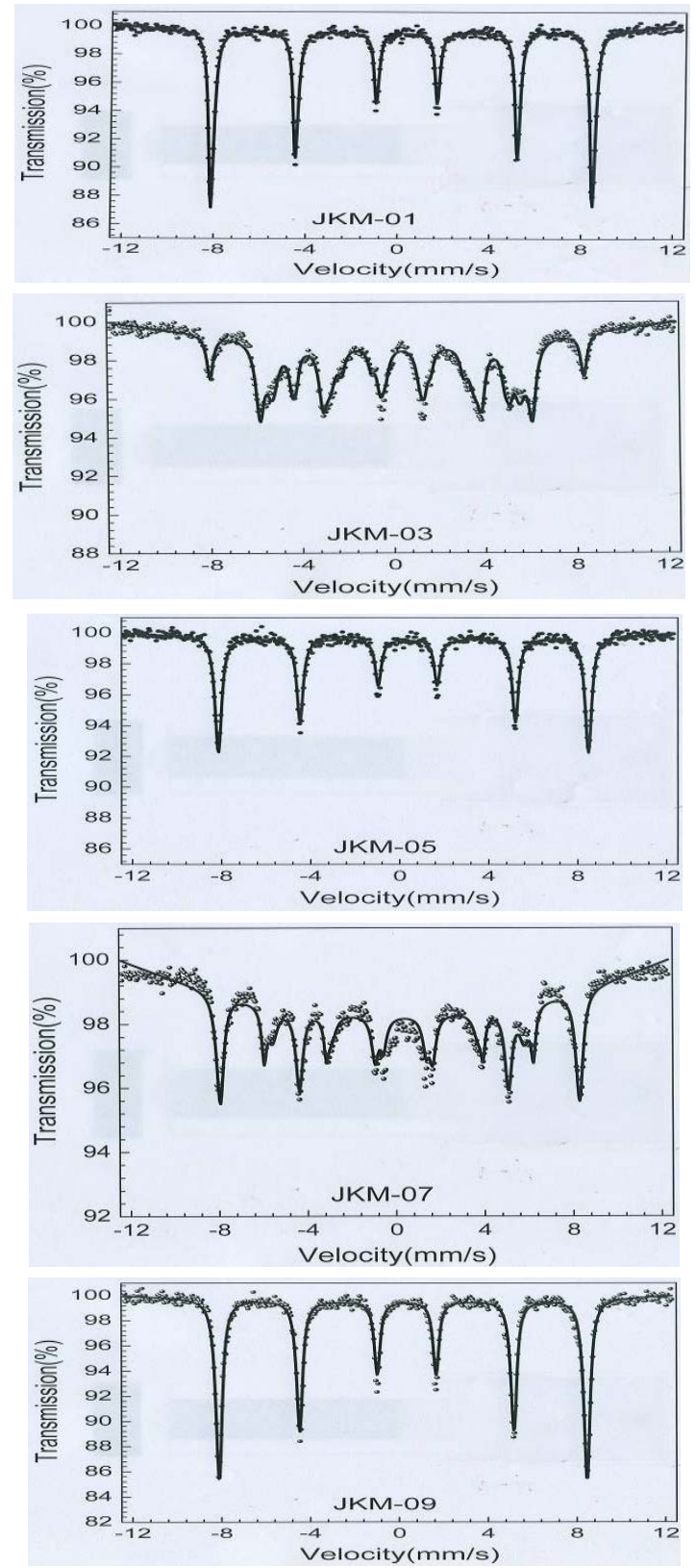

Figure 6. Mossbauer spectra of iron ore samples from different iron formations.
Presence of minor amounts of goethite is also observed.

\subsection{Mossbauer Study}

Mossbauer spectroscopy has been used for identification of iron bearing mineral phases [3]. Earlier workers have reported mineralogy of Iron ores from banded iron formations of Orissa by means of Mossbauer spectroscopy [4]. For the present investigation, selected samples from three iron ore formations were taken for Mossbauer study. The spectra and results of MS study were given in Figure 6 and Table 1.

From the above study, it is observed that samples from
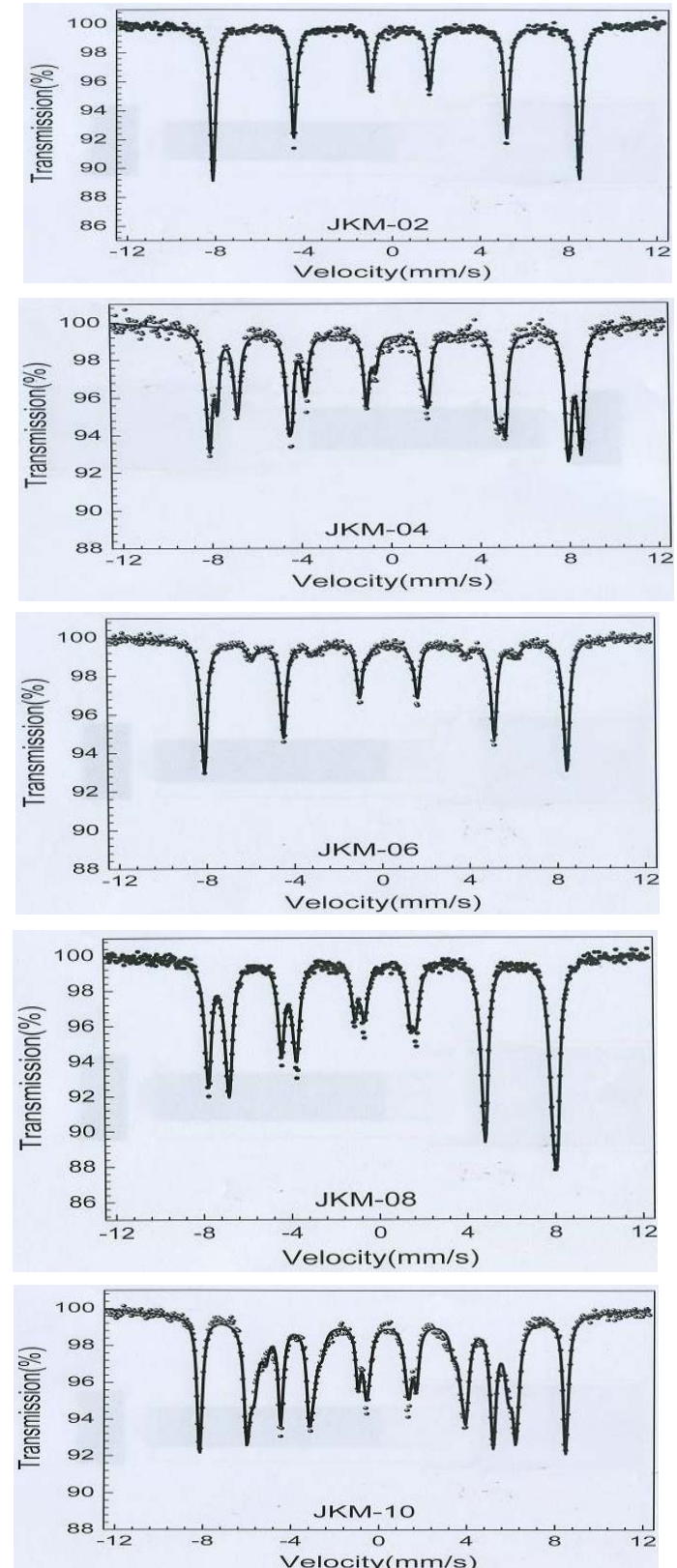
Table 1. Mossbauer parameters of iron ore samples from different iron formations.

\begin{tabular}{|c|c|c|c|c|c|c|}
\hline Sl. No. & IS (mm/s) & $\mathrm{QS}(\mathrm{mm} / \mathrm{s})$ & LWD (mm/s) & $\operatorname{Bhf}(\mathrm{T})$ & Area (\%) & Mineral \\
\hline JKM-1 & 0.3489 & -0.0940 & 0.2648 & 51.6 & 100 & Hematite \\
\hline JKM2 & 0.3496 & -0.0924 & 0.2596 & 51.6 & 100 & Hematite \\
\hline \multirow[t]{4}{*}{ JKM3 } & 0.3411 & -0.0812 & 0.3103 & 50.7 & 16.8 & Hematite \\
\hline & 0.3370 & -0.1349 & 0.3811 & 37 & 33.8 & Goethite \\
\hline & 0.3387 & -0.1353 & 0.3784 & 33.6 & 36.9 & Goethite \\
\hline & 0.4512 & -0.0514 & 0.3307 & 28.4 & 12.5 & Unknown \\
\hline \multirow[t]{3}{*}{ JKM4 } & 0.3497 & -0.0431 & 0.3041 & 51.6 & 47.2 & Hematite \\
\hline & 0.2221 & -0.0408 & 0.2064 & 48.6 & 17.3 & Magnetite \\
\hline & 0.6673 & 0.0188 & 0.3258 & 46.2 & 35.5 & Magnetite \\
\hline JKM5 & 0.3490 & -0.0962 & 0.3307 & 51.6 & 100 & Hematite \\
\hline \multirow[t]{2}{*}{ JKM6 } & 0.3478 & -0.0796 & 0.3051 & 51.3 & 85.3 & Hematite \\
\hline & 0.3478 & -0.1374 & 0.4555 & 37.5 & 14.7 & Goethite \\
\hline \multirow[t]{3}{*}{ JKM7 } & 0.3474 & -0.0953 & 0.3699 & 50.4 & 59.5 & Hematite \\
\hline & 0.3448 & -0.1344 & 0.2328 & 37.8 & 16.7 & Goethite \\
\hline & 0.3397 & -0.1445 & 0.4983 & 35.4 & 23.9 & Goethite \\
\hline \multirow[t]{2}{*}{ JKM8 } & 0.2698 & -0.0067 & 0.3278 & 49.3 & 44.3 & Magnetite \\
\hline & 0.6360 & 0.0059 & 0.3783 & 45.8 & 55.7 & Magnetite \\
\hline JKM9 & 0.3498 & -0.0870 & 0.3195 & 51.5 & 100 & Hematite \\
\hline \multirow[t]{4}{*}{ JKM10 } & 0.3553 & -0.1037 & 0.2626 & 51.6 & 35.2 & Hematite \\
\hline & 0.3402 & -0.1393 & 0.3006 & 38 & 30.3 & Goethite \\
\hline & 0.3309 & -0.1387 & 0.4294 & 36 & 25.1 & Goethite \\
\hline & 0.2550 & -0.2041 & 0.3307 & 31.8 & 9.4 & Goethite \\
\hline
\end{tabular}

BIF-I (JKM4 \& JKM8), BIF-II (JKM9 \& JKM10), BIF-III (JKM1, JKM2, JKM5 \& JKM6), Hirapur (JKM3 \& JKM7).

BIF 1 mostly consist of magnetite. Samples from BIF 3 have hematite as the principal mineral phase with minor amounts of goethite. Iron ore from BIF 2 consists of hematite and goethite. Iron ore sample from Hirapur contains both hematite and goethite. Qualitative and quantitative estimation of minerals by mossbauer study corroborates the findings of microscopic and XRD study and also gives an idea about the relative abundance of the iron minerals in three iron formations. It also gives an idea about the degree of crystallinity and structural state of the iron minerals. This information along with VSM data may be useful for better understanding of the physical characters of iron minerals, which leads to selection of proper communition as well as beneficiation process.

\subsection{VSM Study}

Natural iron minerals display a very wide range of magnetic properties. The minerals can be satisfactorily dis- tinguished from one another by laboratory induced magnetization at room temperature [5]. The hysteresis curves (Figure 7) and relevant data generated by VSM study are given in Table 2. The VSM data indicate that samples from BIF 1 possess magnetic character due to presence of magnetite as the principal iron mineral. Samples from BIF 2 have some magnetic behaviour due to presence of minor to trace amounts of magnetite/martite. Samples from BIF 3 and Hirapur are less to nonmagnetic in character. This indicates that samples from different iron formations have differential magnetic behaviour and need differential heating to simulate magnetism in them which will help in their separation from the associated gangue mineral, quartz (highly nonmagnetic) during beneficiation process. Undoubtedly the results from VSM studies give an indication for selection of the type of magnetic separator to be used based on the magnetic intensity range for its up-gradation. 

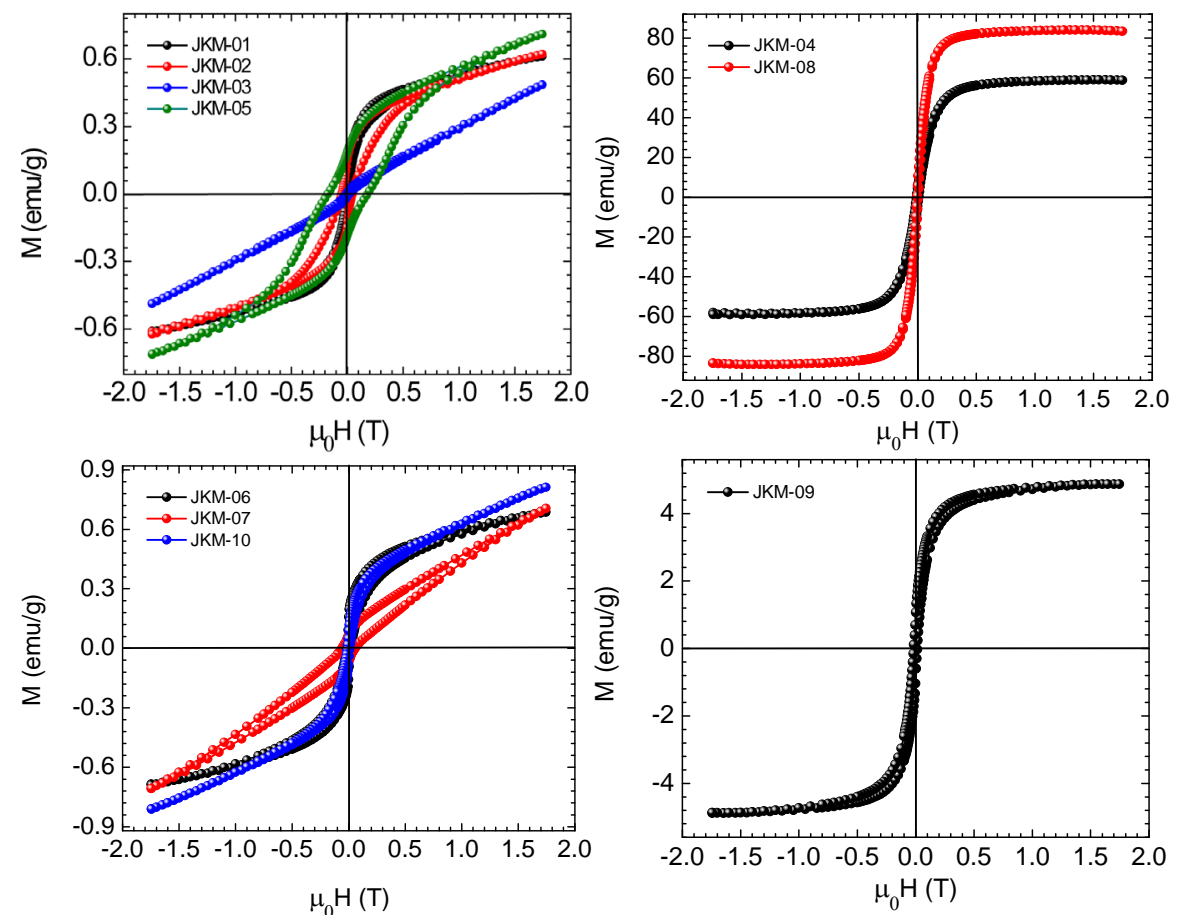

Figure 7. Hysteresis curves for different iron ore samples.

Table 2. VSM data of iron ore samples.

\begin{tabular}{cccc}
\hline Sample & Magnetization at 1.75 Tesla, Ms (emu/g) & Remanent Magnetization, Mr (emu/g) & Coercive field, Hc (Oe) \\
\hline JKM1 & 0.6112 & 0.06825 & 88.92 \\
JKM2 & 0.6215 & 0.1464 & 474.46 \\
JKM3 & 0.4862 & 0.009 & 121.36 \\
JKM4 & 59.01 & 4.363 & 89.63 \\
JKM5 & 0.7105 & 0.1861 & 1775.2 \\
JKM6 & 0.6877 & 0.1571 & 197.69 \\
JKM7 & 0.7067 & 0.07348 & 557.88 \\
JKM8 & 84.07 & 5.872 & 56.75 \\
JKM9 & 4.877 & 1.049 & 162.46 \\
JKM10 & 0.8119 & 0.0847 & 122.17 \\
\hline
\end{tabular}

(Sample Nos are same as given in Table 1).

\subsection{Chemical Analysis}

Chemical analysis data indicate the beneficiation process as well as operating parameters to be adopted, number of stages required for cleaning, grade, recovery and cost of the products, evaluation of process etc. Chemical analysis of the concentrate and rejects helps the researchers/industrialists to evaluate and develop the process flowsheet. Keeping this in mind, representative samples from different BIFs are analysed for their major element composition by XRF. The major elements data are given below in Table 3 .

It is observed that $\mathrm{SiO}_{2}$ varies from $1 \%$ in massive ore to $75 \%$ in siliceous ore. Similarly $\mathrm{Fe}_{2} \mathrm{O}_{3}$ varies from $21.38 \%$ in siliceous ore to around $97 \%$ in massive ore. However within these extremes, both silica and iron exhibit wide variation and the relative proportion of these elements affect the grade and demand of the ore. $\mathrm{Al}_{2} \mathrm{O}_{3}$ is invariably less which is a characteristic of banded iron formations. Other elements like Mn, Mg, Ca, Na, K, Ti and $\mathrm{P}$ are present in very trace amount.

\section{Beneficiation Study}

BHQ and BHJ constitute around 35\% of the iron ore reserve. Although India is blessed with large reserves of 
Table 3. Chemical analysis of iron ore samples.

\begin{tabular}{ccccccccccccc}
\hline Sl.No. & $\mathrm{SiO}_{2}$ & $\mathrm{Al}_{2} \mathrm{O}_{3}$ & $\mathrm{Fe}_{2} \mathrm{O}_{3}$ & $\mathrm{MnO}$ & $\mathrm{MgO}$ & $\mathrm{CaO}$ & $\mathrm{Na}_{2} \mathrm{O}$ & $\mathrm{K}_{2} \mathrm{O}$ & $\mathrm{TiO}_{2}$ & $\mathrm{P}_{2} \mathrm{O}_{5}$ & $\mathrm{LOI}^{*}$ & $\mathrm{Sum}^{2}$ \\
\hline JKM1 & 75.76 & 1.25 & 21.38 & 0.02 & 0.04 & 0.14 & 0.07 & 0.01 & 0.03 & 0.06 & 2.25 & 101.01 \\
$\mathrm{JKM} 2$ & 29.68 & 0.21 & 68.97 & 0.11 & 0.05 & 0.14 & 0.01 & 0.01 & 0.03 & 0.08 & 1.41 & 100.7 \\
$\mathrm{JKM} 3$ & 1.52 & 0.71 & 86.25 & 0.22 & 0.06 & 0.24 & 0.01 & 0.01 & 0.04 & 0.33 & 11.12 & 100.51 \\
JKM4 & 12.58 & 0.41 & 82.97 & 0.26 & 1.34 & 0.66 & 0.01 & 0.01 & 0.03 & 0.06 & 1.23 & 99.56 \\
JKM5 & 1.23 & 0.59 & 96.81 & 0.03 & 0.01 & 0.02 & 0.01 & 0.02 & & 0.04 & 1.53 & 100.29 \\
JKM6 & 49.54 & 0.15 & 45.72 & 0.1 & 0.05 & 0.1 & 0.01 & 0 & 0.01 & 0.06 & 2.44 & 98.18 \\
JKM7 & 1.34 & 1.30 & 84.62 & 0.22 & 0.10 & 0.30 & 0.01 & 0.03 & 0.46 & 0.30 & 11.91 & 100.59 \\
JKM8 & 1.02 & 0.10 & 96.42 & 0.39 & 0.23 & 0.04 & 0.01 & 0.01 & 0.02 & 0.05 & 0 & 98.27 \\
JKM9 & 28.49 & 0.17 & 70.10 & 0.02 & 0.03 & 0.04 & 0.02 & 0.01 & 0.04 & 0.06 & 2.09 & 101.07 \\
JKM10 & 1.21 & 0.17 & 97.16 & 0.06 & 0.11 & 0.03 & 0.01 & 0.01 & 0.02 & 0.20 & 0.85 & 107.83 \\
\hline
\end{tabular}

( $\mathrm{LOI}$ is done at $950^{\circ} \mathrm{C}$ ) (Sample No. same as given in Table 1).

iron ore containing average grade around $58 \% \mathrm{Fe}$, the performance of blast furnaces has been at lower levels in comparison with developing countries. This is mainly due to the presence of high levels of impurities such as silica and alumina in the raw material contradicting to blast furnace chemistry.

In order to increase the efficiency of blast furnace, some of the issues relating to iron ores include chemical composition of iron ore with low Fe content and high Al:Si ratio, low strength, high temperature breakdown, low reducibility, low temperature softening and melting behaviour of iron ores, etc. Normally iron ores with $65 \% \mathrm{Fe}$ are desirable to achieve better productivity either in blast furnace or direct reduction. The other impurities level such as $\mathrm{Na}, \mathrm{K}, \mathrm{S}$ and $\mathrm{P}$ should be as low as possible. Alumina and silica content should be within permissible limit for better fluidity of slag. Due to decrease in good quality iron ore, the Run-Off Mine (ROM) ore with low Fe content needs beneficiation to lower the impurities to improve the strength of sinter and pellet quality. The physical, chemical and metallurgical properties of lumps, sinters and pellets are important as they have a significant impact on furnace performance.

Iron ore is being beneficiated all around the world to meet the quality requirement of iron and steel industries. However, each source of iron has its own peculiar mineralogical characteristics and requires specific beneficiation and metallurgical treatment to get the best product out of it. The choice of beneficiation treatment depends on the nature of the gangue present and its association with the ore. Several techniques such as washing, jigging, magnetic separation, gravity separation and flotation are being employed to enhance the quality of the iron ore. Washing, jigging and classification are being carried out for the beneficiation of iron ores in India $[6,7]$.
During washing and sizing of the ore, slimes with less than $0.21 \mathrm{~mm}$ size are generated and discarded into the tailing pond. It is estimated that around 10 million tones of slimes are being generated every year during the processing of hematite ore and lost as tailings containing around $48 \%$ - 62\% Fe. However, beneficiation and utilization of these slimes still remains as a challenging task.

In this context, two low grade iron ore samples of siliceous nature (one BHJ and another BHQ) collected from the iron ore formations of Orissa are taken up for their up gradation of iron values by suitable beneficiation techniques. One sample of BMQ having $40 \%$ Fe was upgraded up to $63 \% \mathrm{Fe}$ with a yield of $52 \%$, while the rejection is around $17 \% \mathrm{Fe}$. Similarly, another sample of BHQ having $35 \%$ Fe is upgraded to $61 \% \mathrm{Fe}$ at $44 \%$ yield with iron values of $16 \% \mathrm{Fe}$ in the discarded tailings. A lot of iron values are lost in the slimes also which indicates the poor liberation of iron and silica in the feed material. This is because of the fact that the silicate grains in magnetite/hematite are very fine grained as revealed by SEM. Over grinding to get more iron minerals in liberated form results, more slime generation. Even though there is an increase in the grade of iron in the product, the benefit of this is being somewhat compensated by the energy consumption during grinding and also in slime treatment.

\section{Conclusion}

Characterisation of iron ore is essential for its optimum utilization. Demand for good grade iron ore is on rise and the reserve is limited. So utilization of low and medium grade iron ores especially BHJ/BHQ is a necessity. Effective utilization of this type of iron ores can not be achieved with out a proper assessment of the material in respect of texture and mineralogy. This necessitates a 
detail ore characterisation which will help in understanding the mineralogical response during processing of the ore. A combined approach of optical \& electron microscopic study, XRD and Mossbauer \& VSM study of the iron ores from different iron formations (where huge amounts of low to medium grade iron ores are available) will give a better insight to the different mineralogical attributes of the ore and their bearing on processing of the ore and optimum utilization. The present study highlights the major minerals and their textural behaviour such as relation between hematite and quartz and their spatial distribution in the ore. It is observed that separation of macrobands is easy but to get a good grade of iron concentrate from an ore having microbanding is difficult due to intimate association of hematite and quartz on a very fine scale. Presence of hematite in quartz and viceversa also affects the complete separation. So the integrated mineralogical study is very important as it gives an insight into the beneficiation process to be adopted and its cost effectiveness.

\section{Acknowledgements}

The authors thank Director, CSIR-IMMT Bhubaneswar for permission to publish this paper. This work is carried out as a part of CSIR Network Program (NWP-31).

\section{REFERENCES}

[1] Indian Minerals Yearbook, Indian Bureau of Mines, Go- vernment of India, 2008.

[2] S. Roy and A. S. Venkatesh, "Mineralogy and Geochemistry of Banded Iron Formation and Iron Ore from Eastern India with Implication on Their Genesis,” Journal of Earth System Science, Vol. 118, No. 6, 2009, pp. 619-641. doi:10.1007/s12040-009-0056-Z

[3] G. M. Brancroft, "Mossbauer Spectroscopy," McGrawHill, Maidenhead, 1973.

[4] P. K. Nayak, D. Das, V. Vijayan, P. Singh and V. Chakravorty, ${ }^{{ }^{57}}$ Fe Mossbauer and EDXRF Studies on Three Representative Banded Iron Formations (BIFs) of Orissa, India," Nuclear Instruments and Methods in Physics Research Section B, Vol. 184, No. 4, 2001, pp. 649-654.

[5] C. Peters and R. Thompson, "Magnetic Identification of Selected Natural Iron Oxides and Sulphides,” Journal of Magnetism and Magnetic Materials, Vol. 183, No. 4, 1998, pp. 365-374. doi:10.1016/S0304-8853(97)01097-4

[6] B. Roy, "Utilization of India's Iron Ore Resources-Present Situation and Future Possibilities," Proceeding of the IX International Seminar on Mineral Processing Technology (MPT-2010), Jamshedpur, 15-17 December 2010, pp. 535-541.

[7] B. Das, S. Prakash, S. K. Das and P. S. R. Reddy, "Effective Beneficiation of Low Grade Iron Ore through Jigging Operation," Journal of Minerals and Materials Characterisation and Engineering, Vol. 7, No. 1, 2008, pp. 2737. 